\title{
PERENCANAAN INSTALASI PENGOLAHAN AIR LIMBAH (IPAL) STUDI KASUS PROYEK IPAL PT.SUMBER MASANDA JAYA DI KABUPATEN BREBES PROFINSI JAWA TENGAH KAPASITAS $250 \mathrm{~m}^{2} /$ HARI
}

\author{
ALMUFID $^{1)}$, \& RULLY PERMADI ${ }^{2)}$ \\ Universitas Muhammadiyah Tangerang Indonesia \\ Jl. Perintis Kemerdekaan I, No.33 Cikokol Tangerang 15118 \\ 1) Dosen, Jurusan Teknik Sipil, Universitas Muhammadiyah Tangerang \\ ${ }^{2)}$ Mahasiswa, Jurusan Teknik Sipil, Universitas Muhammadiyah Tangerang \\ Email: almufid_st@yahoo.com, ${ }^{1)}$ permadi_rully@yahoo.co.id ${ }^{2)}$
}

\begin{abstract}
ABSTRAK
Masalah pencemaran lingkungan, khursusnya pencemaran air di kota-kota besar di Indonesia, telah menunjukan gejala yang cukup serius. Penyebab dari pencemaran ini tidak hanya berasal dari buangan industrif, yang membuang begitu saja air limbahnya tanpa pengolahan lebih dahulu ke sungai atau ke laut, tetapi juga oleh air limbah domestik yang jumlahnya semakin besar sejalan dengan perkembangan penduduk maupun perkembangan kota. Teknologi pegolahan air limbah: teori dan aplikasi hadir sebagai buku yang membahas tentang teknologi pengolahan air limbah ditinjau dari sudut teori dan aplikasi praktis di lapangan.
\end{abstract}

Kata Kunci: Sistem Pengolahan Air Limbah Domestik Industri (IPAL) Domestik, Teknologi Pengelolaan Air Limbah.

\begin{abstract}
The problem of environmental pollution, especially water pollution in big cities in Indonesia, shows some serious symptoms. The cause of this contamination comes not only from industrial waste, which discharges its waste without prior treatment into the river or sea, but also by growing domestic waste in line with population growth and urban development. Wastewater treatment technology: Theory and application present as a book that discusses the theory of practical wastewater and practical applications in the field.
\end{abstract}

Keywords: Domestic Industrial Waste Management System (WWTP)Domestic, Wastewater treatment technology.

\section{PENDAHULUAN}

Pertumbuhan penduduk di Indonesia yang begitu cepat terutama di wilayah perkotaan memberikan dampak yang sangat serius terhadap penurunan daya dukung lingkungan. Terlebih lagi arus urbanisasi perkotaan yang terus mengalami peningkatan menyebabkan proporsi penduduk perkotaan mengingat secara tajam. Hal ini diperkirakan terus terjadi, sehingga diperkirakan pada tahun 2025 penduduk Indonesia diperkerikan akan mendiami perkotaan. Urbanisasi yang tinggi ini seringkali sulit diiringi dengan pengem- bangan prasmanan dan sarana pengolahan air limbah. Dampak tersebut harus disikapi dengan tepat, khursusnya dalam pengolahan air limbah, oleh karena kenaikan jumlah penduduk dan meningkatkan konsumsi pemakaian air minum/bersih yang berdampak pada peningkatan jumlah air limbah. Pembuangan air limbah tanpa melalui proses pengolahan akan mengakibatkan terjadinya pencemaran pada sumber-seumber air baku untuk air minum baik air permukaan maupun air tanah.

Kabupaten Brebes provinsi jawa tengah menunjukan gejala serius pada masalah pen- 
cemaran lingkungan, khursusnya pencemaran air. Penyebab dari pencemaran tadi tidak hanya berasal dari buangan industri dari pabrikpabrik yang membuang begitu saja air limbahnya tanpa pengolahan terlebih dahulu ke sungai atau ke laut, tetapi juga yang tidak kalah memegang andil baik secara sengaja atau tidak adalah penduduk Kabupaten Brebes Provinsi Jawa Tengah itu sendiri. Setiap hari buangan rumah tangga yang jumlahnya semakin besar sesuai dengan perkembangan penduduk maupun perkembangan Kabupaten Brebes.

Sebagai persoalan lingkungan di Kabupaten Brebes memiliki hubungan yang signifikan dengan kondisi cakupan layanan sanitasi bagi masyarakat yang belum merata dan belum menggambarkan kualitas yang memenuhi standar. Beberapa hal yang mendorong terjadinya hal di atas, juga disebabkan lemahnya perencanaan pembangunan sanitasi, tidak sesuai kebutuhan, tidak berkelanjutan serta kurangnya perhatian masyarakat pada perilaku hidup bersih dan sehat.

Pengertian sanitasi itu sendiri adalah perilaku yang disengaja dalam pembudayaan hidup bersih dengan maksud mencegah manusia bersentuh langsung dengan kotoran dan bahan buangan berbahaya lainya dengan harapan usaha ini akan menjaga dan meningkatkan kesehatan manusia. Salah satu upaya memperbaiki kondisi sanitasi adalah dengan menyiapkan sebuah perencanaan pembanguan sanitasi yang responsif dan berkelanjutan.

Salah satu contoh permasalahan sanitasi yang paling banyak terjadi dan berhubungan langsung dengan masyarakat adalah air limbah Industri. Menurut Keputusan Mentri Negara Lingkungan Hidup Nomor 32 tahun 2009 tentang baku mutu air limbah yang berasal dari pabrik dan kegiatan perindustrian atau rumah sakit dan perhotelan.

Air limbah atau air buangan adalah sisa air yang di buang berasal dari industri maupun tempat-tempat umum lainya, dan pada umumnya mengandung bahan-bahan atau zat-zat yang dapat membahayakan bagi kesehatan manusia serta menggangu lingkungan hidup. Batasan lain mengatakan bahwa air limbah adalah kombinasi dari cairan dan sampah cair yang berasal dari daerah pemukiman, perdagangan, perkantoran, dan industri bersamasama dengan air tanah, air permukaan dan air hujan yang mungkin ada. Dengan demikian setiap air limbah yang dihasilkan perlu dikelola secara baik berdasarkan karakteristiknya agar dapat menurunkan kualitas bahan pencemaran yang terkandung di dalamnya sebelum dialirkan ke badan sungai agar tidak mencemari lingkungan. Salah satu solusi efisein untuk masalah ini adalah pembuatan IPAL (Instalasi Pengolahan Air Limbah).

\section{TINJAUAN PUSTAKA \\ 1. Definisi Air limbah dan Air limbah Domestik}

Air limbah adalah kotoran dari masyarakat dan rumah tangga dan juga berasal dari industri, air tanah, air permukaan serta buangan lainnya. Dengan demikian air buangan ini merupakan hal yang bersifat kotoran umum, air limbah adalah air dari suatu daerah yang telah dipergunakan untuk berbagai keperluan, harus dikumpulkan dan dibuang untuk menjaga lingkungan hidup yang sehat dan baik.

Air limbah adalah cairan yang berasal dari rumah tangga, industri ataupun tempat-tempat umum lainnya yang biasanya mengandung bahan atau zat-zat yang dapat membahayakan hidup manusia serta menggangu kelestarian lingkungan. Sumber serta macam air limbah dapat di pengaruhi oleh tingkat hidup masyarakat. Semakin tinggi tingkat ekonomi masyarakat beragam pula air limbah yang dihasilkan.

Air limbah adalah air yang tidak bersih/ mengandung berbagai zat yang bersifat membahayakan kehidupan manusia atau hewan. Lazimnya muncul akibat hasil perbuatan manusia (termasuk industrialisasi). Sisa air yang di buang berasal dari rumah tangga, industri, maupun tempat umum lainnya kementrian lingkungan hidup (2003) mendefinisikan air limbah domestik sebagai air limbah yang berasal dari perumahan atau pemukiman, perkantoran, pusat perbelanjaan/ perdagangan, restaurant/rumah sakit, dan industri. Air limbah domestik tidak bisa dibuang begitu saja ke badan air tanpa ada pengolahan terlebih dahulu karena akan mencemari kualitas air dan air tanah.

Limbah domestik adalah air buangan yang berasal dari penggunaan untuk kebersihan yaitu gabungan limbah dapur, kamar mandi, toilet, cucian dan sebagainya. Komposisi limbah cair rata-rata mengandung bahan organik dan senyawa mineral yang berasal dari 
sisa makanan, urin dan sabun yang biasanya banyak dihasilkan dari limbah industri tersebut.

Perkembangan penduduk kota-kota besar semakin meningkat pesatnya, seiring dengan pesatnya laju pembangunan, sehingga jumlah limbah domestik yang dihasilkan juga semakin besar. Sedangkan daya dukung sungai atau badan air penerima limbah domestik yang ada justru cenderung menurun dilihat dari terus menurunnya debit sungai tersebut.

\section{Dampak Negatif Air Limbah Domestik.}

Air limbah yang tidak dikelola dengan baik dapat menumbulkan dampak buruk bagi mahluk hidup dan lingkungannya. Beberapa dampak buruk tersebut antara lain sebagai berikut:

a) Gangguan kesehatan;

b) Penurunan kualitas lingkungan;

c) Gangguan terhadap keindahan; dan

d) Gangguan kerusakan benda.

\section{Instalasi Pengolahan Air Limbah Domestik}

Instalasi pengolahan air limbah, yang selanjutnya akan disingkat IPAL, merupakan sistem pengolahan air limbah yang dilakukan secara terpusat yaitu terhadap bangunan yang digunakan untuk memproses limbah cair domestik yang difungsikan secara baik, agar lebih aman pada saat dibuang kelingkungan sesuai dengan baku mutu lingkungan.

Effluent dari instalasi pengolahan dapat disalurkan menuju sumur resapan atau juga dapat dibuang ke badan sungai. Fasilitas sistem ini di bangun untuk menghidari pecemaran air limbah agar tidak mencemari lingkungan. Bangunan pengolahan air limbah ini bisa diterapkan di berbagai perindustrian yang memiliki ancaman penecmaran limbah.

Untuk lebih jelasnya, tahapan proses Flowchart ipal tersebut dapat dilihat pada Gambar 2.1 dibawah ini.

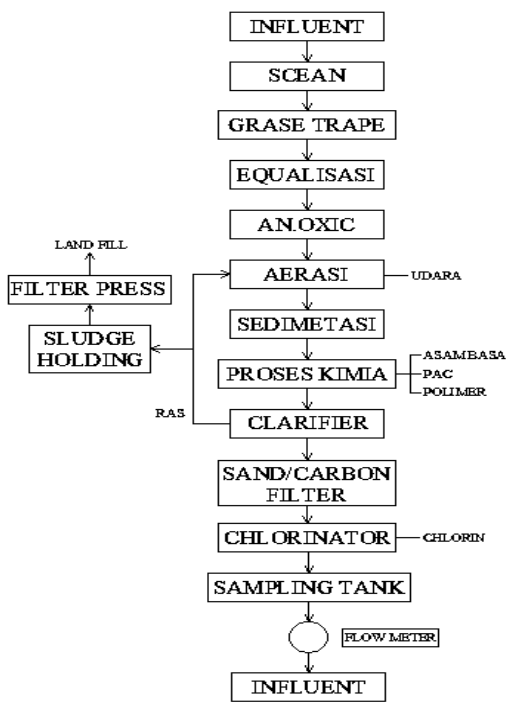

Gambar 2.1 diagram proses instalasi pengolahan air limbah (IPAL).

Sumber: Panduan Training IPAL, PT. National Environmental Technologi

4. Tahapan Proses dan design bak IPAL kapasitas $250 \mathrm{~m}^{3} /$ hari

a) Bak Screan.
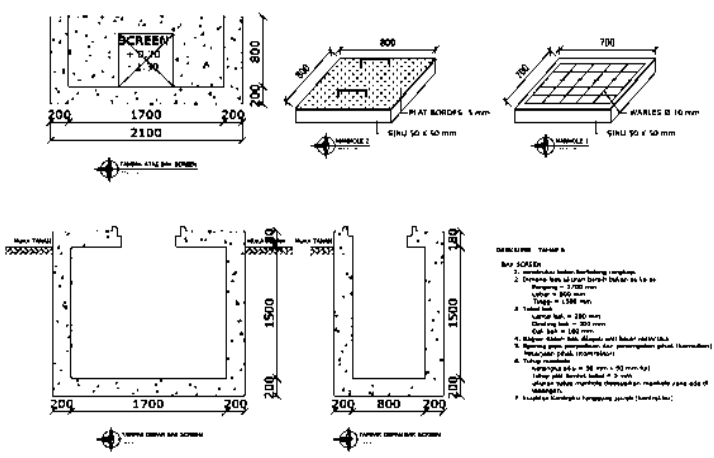

Fungsi: Untuk menyaring air limbah yang masuk dari awal atau inlet dari sampah padat yang terbawa oleh buangan agar tidak tercampur dan masuk kedalam sistem pengolahan air limbah yang akan di kelolah.

b) Bak Grase Trape.

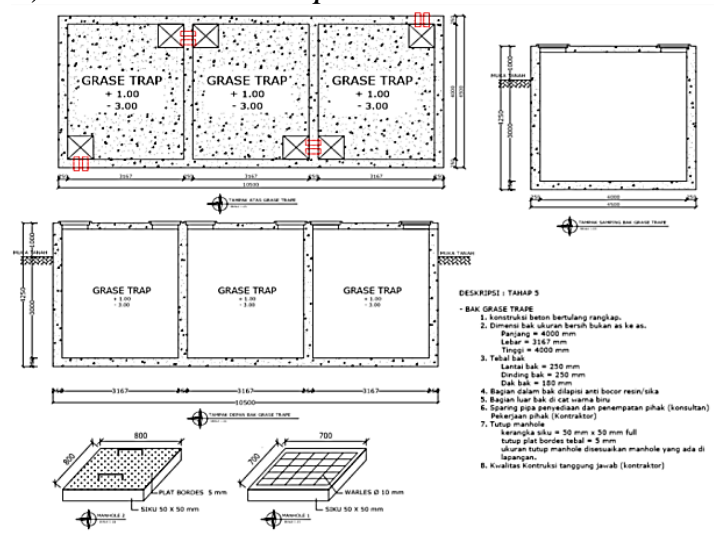


Fungsi: Untuk memisahkan antara lemak dan air limbah yang terbawa oleh buangan maka dapat di pisahkan menggunakan sistem grase trape tersebut yang efektif agar memudahkan dalam pemprosesan air limbah.

c) Bak Equalisasi.
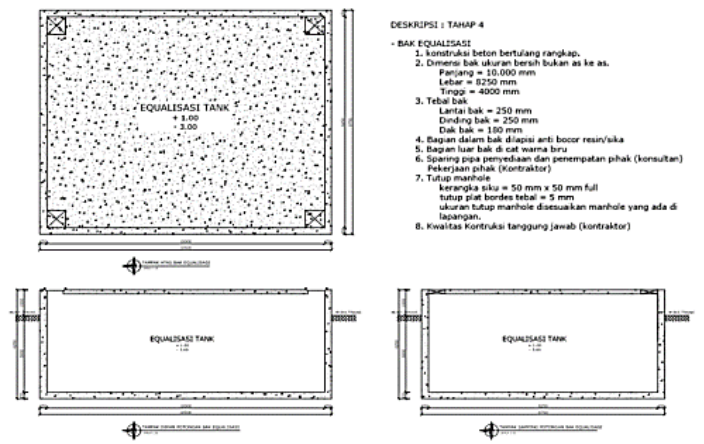

Fungsi: Proses ini berfungsi untuk menghomogenkan atau menyeragamkan pencemaran air limbah yang setiap menitnya mengalami fluktuaktif kadarnya yang berasal dari proses produksi dan laboratorium, sehingga dengan seragamnya kadar parameter air limbah yang ada dibak equalisasi akan mempermudah untuk proses pengolahannya.

d) Bak An.Oxic
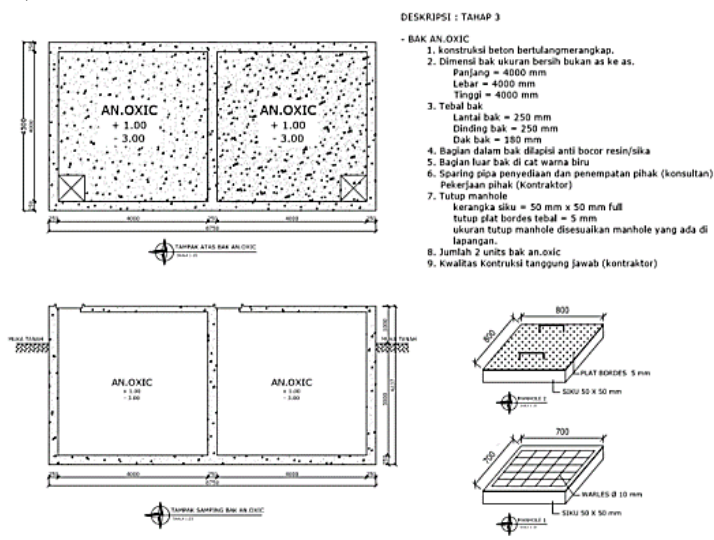

Fungsi: Suatu proses pengolahan yang kondisinya tidak terdapat oksigen terlarut lagi, sehingga microrganisme mengolah air limbah perlu melepaskan oksigen terkait dalam bentuk senyawa nitrat atau nitrit. e) Bak Aerasi

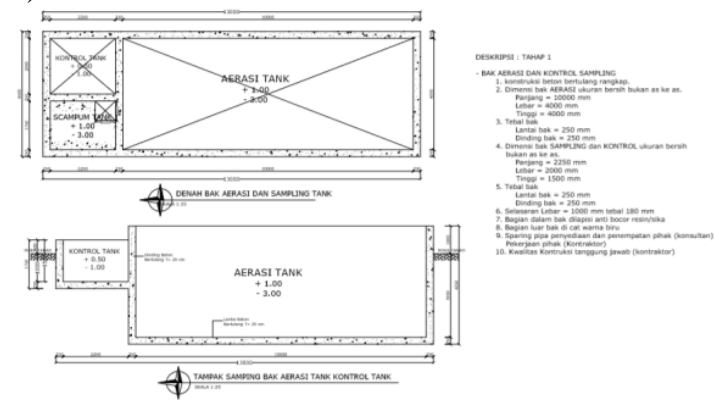

Fungsi: Sebelum melewati proses aerasi ini, air limbah terlebih dahulu dinetralkan $\mathrm{pH}$ nya, sehingga proses itu berjalan dengan baik. Pada bak aerasi ini terjadi penambahan oxygen kedalam air limbah dengan mengunakan blower dan pada bak ini dilengkapi dengan diffuser sehingga oxygen yang dimasukan kedalam air limbah dapat merata. Pada proses ini juga akan dimanfaatkan jasa bakteri (lumpur aktif) untuk menguraikan bahan organic air limbah, sehingga dapat menurunkan BOD dan COD sampai mencapai $90 \%$.

Proses activated sludge ini dikembangkan di inggris pada tahun 1914 oleh Ardem dan Locket dan dinamakan proses lumpur aktif dari microorganisme yang mampu menstabilisasi air limbah biologis dengan proses lumpur aktif ini dilakukan dengan memasukan limbah organik kedalam bak aerasi yang berisi koloni bakteri yang dijaga dalam keadaan tersuspensi. Isi dari reactor tersebut biasanya disebut sebagai mixed liquor di dalam reactor. Kultur bakteri akan mengkonsumsi limbah organic manjadi senyawa sederhana dengan stokhimoteri.

f) Bak Sedimentasi
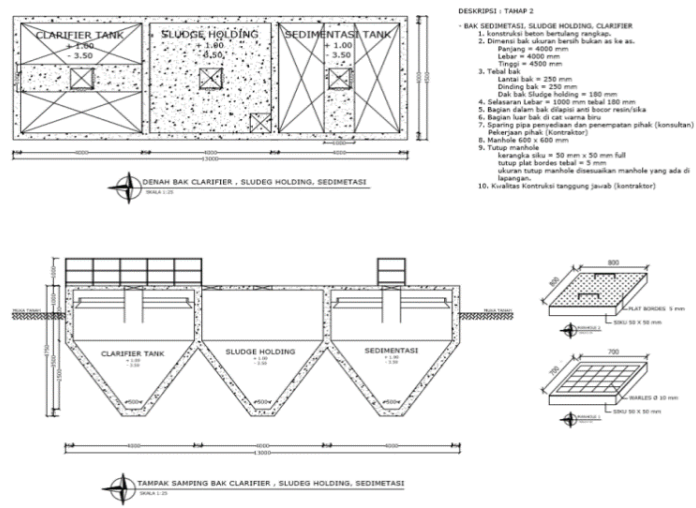

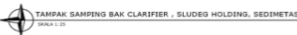


g) Wearing PVC \& Central Wearing
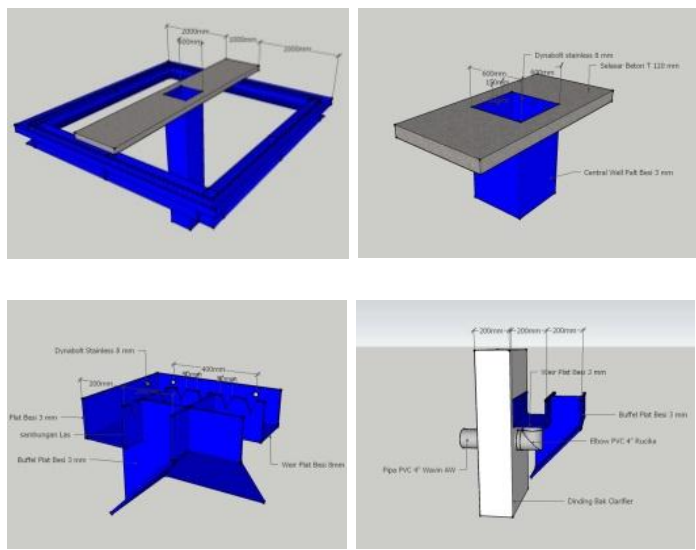

Fungsi: Air limbah yang telah melewati sistem proses aerasi kemudian masuk kedalam bak sedimentasi untuk melalui proses pengendapan gumpalan partikel bakteri yang telah diproses oleh sistem aerasi pengendapan minimal 2.5 jam. Dan setelah itu masuk ke proses kimia yang nantikan akan di campurkan kimia pengikat agar partikel bakteri dan air terpisah.

h) Bak Clarifier.

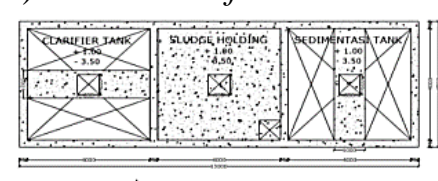

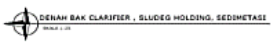

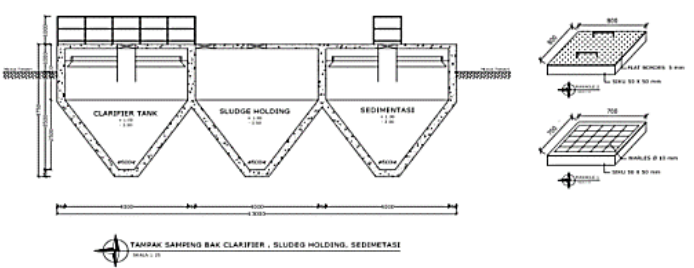

Fungsi: sama fungsi nya seperti sedimentasi, tetapi clarifier di gunakan pada sistem pengendapat akhir dari proses kimia tersebut karena air yang di hasil kan sudah tidak terkontaminasi zat-zat berbahaya lagi.

i) Sand Carbon Filter.

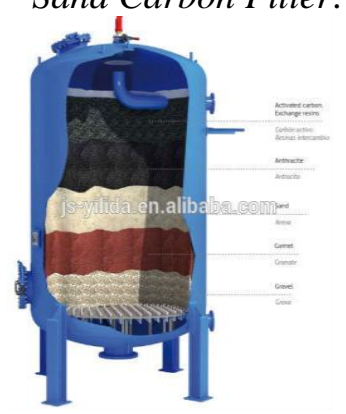

Fungsi: Untuk menurunkan kadar pencemaran parameter yang berada dalam air limbah seperti zat organi, colour dan bau, disamping itu juga berfungsi sebagai penyaring flok-flok yang masih terbawa kesaluran outlet.

\section{j) Chlorinator}

Fungsi: Air limbah yang telah diolah dengan menggunakan proses biologi, sebelum dibuang harus dikurangi jumlah bakterinya. Untuk mengurangi jumlah bakteri tersebut di lakukan proses disenfeksi, yaitu dengan menggunakan larutan kaporit (sodium hipoklorit) atau gas khlorin.

k) Samplik tank dan Kontrol tank.

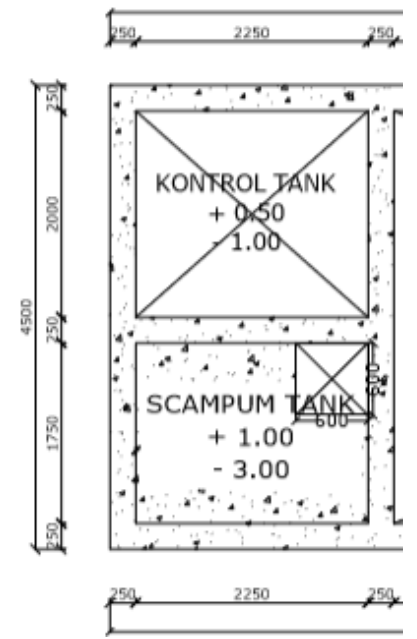

Fungsi: Samplik tank berfungsi untuk pengujian sampel kualitas air limbah setelah melalui proses pada IPAL.

1) Flow Meter.

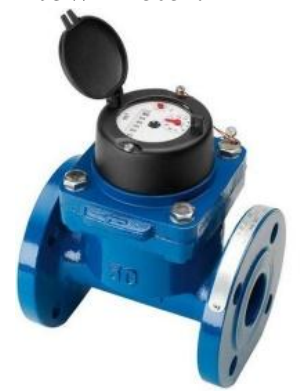

Fungsi: Berfungsi untuk mencatat air limbah yang diolah setiap harinya, dimana yang harus di perhatikan adalah putaran angkanya.

\section{LANDASAN TEORI}

1. Jenis Penelitian

Jenis penelitian yang digunakan adalah Metode Perencanaan konstruksi dan sistem Grase oil trape alir instalasi pengolahan air 
limbah pada PT. Sumber Masanda Jaya, dimana metode ini digunakan untuk memisahkan minyak dan lemak agar dapat mengetahui efektifitas sistem pengolahan air limbah domestik PT.Sumber Masanda Jaya di Kabupaten Brebes Provinsi Jawa Tengah.

\section{Sampel Air Limbah.}

Sampel air limbah pada penelitian ini adalah sampel outlet dari saptictank dan air limbah cucian hasil industri yang berada di PT. Sumber Masanda Jaya, Kabupaten Brebes Provinsi Jawa Tengah.

\section{Metode Pengambilan Sampel.}

Pengambilan sampel air limbah dilakukan pada saat survei air limbah outlet, setelah sampel diambil kemudian sampel tersebut akan diantar ke Laboratorium unilab. Pengambilan sampel air dilakukan pada lokasi saptictank dan pembuangan air cucian.

Alat yang digunakan dalam pengambilan sampel air limbah.

a) 4 buah botol minum air mineral (1500 $\mathrm{ml}$ );

b) Timba/ gayung air;

c) Corong;

d) GPS;

e) Wadah untuk menyimpan botol sampel; dan

f) Sampel air limbah.

\section{Cara Pengambilan Sampel Air Limbah}

Mengingat pentingnya data hasil uji kualitas baku mutu air limbah, maka dalam proses pengambilan sampel sebagai langkah awal untuk menghasilkan data kualitas baku mutu air limbah harus dipertimbangkan kaidahkaidah ilmiah dan peraturan perundang-undangan lingkungan hidup yang berlaku.

Jika proses pengambilan sampel dilakukan kurang tepat, peralatan atau instrument secanggih apapun yang digunakan tidak dapat menghasilkan data yang menggambarkan kualitas sesungguhnya, kecuali data dari sampel yang seharusnya diuji untuk mendapatkan hasil data yang baik.

Sampel air limbah diambil dari lokasi pembungan air limbah akhir baik itu saptictank maupun bak kontrol pembuangan air cucian yang berada pada PT. Sumber Masanda Jaya Kabupaten Brebes. Sebelumnya peneliti menyiapkan peralatan pengambilan sampel pada titik bak control atau septictank. Langkahlangkah yang perlu diperhatikan saat peng- ambilan sampel air limbah adalah sebagai berikut:

a) Menggunakan botol mineral untuk wadah sampel;

b) Kemudian masukan sampel air limbah ke botol mineral; dan

c) Memberikan label untuk tiap sampel yang diambil.

Setelah dilakukan pengujian di laboratorium disitulah kita akan mengetahui kualitas air limbah yang telah diuji, untuk menentukan kapasitas maksimum agar pada saat medesign kontruksi bangunan ipal tidak over kapasitas.

\section{Baku Mutu Air limbah}

Baku Mutu Air Limbah Domestik Permen LHK Nomor P.68/Menlhk/Setjen/Kum.1/8/ 2016.

\begin{tabular}{|c|c|c|c|c|c|}
\hline №. & $\begin{array}{l}\text { Parameter Uj } \\
\text { Parameters }\end{array}$ & $\begin{array}{l}\text { Baku Mutu } \\
\text { Ret. Gov. Sitd }\end{array}$ & $\begin{array}{l}\text { Hasil Vi } \\
\text { Result }\end{array}$ & $\begin{array}{c}\text { Satuan } \\
\text { Unit }\end{array}$ & $\begin{array}{l}\text { Metode } \\
\text { Method }\end{array}$ \\
\hline 1 & $\left.\mathrm{pH}(\mathrm{Lab})^{\mathrm{N}}\right)$ & - & 7,07 & - & SN $106-6989.11-2004$ \\
\hline 2 & $\mathrm{BOO}_{5}$ & 30 & 16 & $\mathrm{mgl}$ & SNI 6989.72:2009 \\
\hline 3 & $\left.\mathrm{COO}^{\circ}\right)$ & 100 & 52 & $\mathrm{mgl}$ & SNI 6989.22009 \\
\hline 4 & Zat Padat Tersuspensi (TSS) & 30 & 4 & mel & IKM.KHT- 41 (Spekitrofotometri) \\
\hline 5 & Minyak \& Lemak & 5 & $<0,2$ & $\mathrm{mgl}$ & 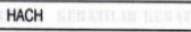 \\
\hline 6 & Amonia $\left.\left(\mathrm{NH}_{5}-\mathrm{N}\right)^{*}\right)$ & 10 & 1 & mel & SN1 06-6989.30-2005 \\
\hline 7 & Total Bakteri Collifom & 3.000 & 540 & MPN100m & APHA $22^{x} 9221$ B-2012 \\
\hline
\end{tabular}

6. Flow Sheet IPAL Domestik PT.Sumber Masanda Jaya

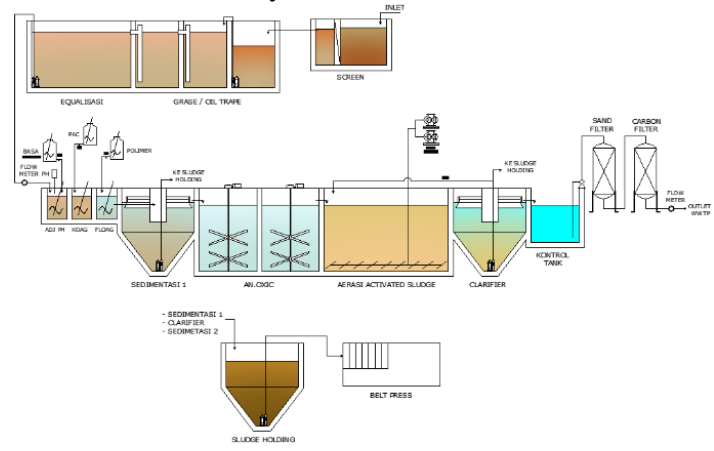

7. Peraturan dan Ketentuan yang Telah Ditetapkan SNI

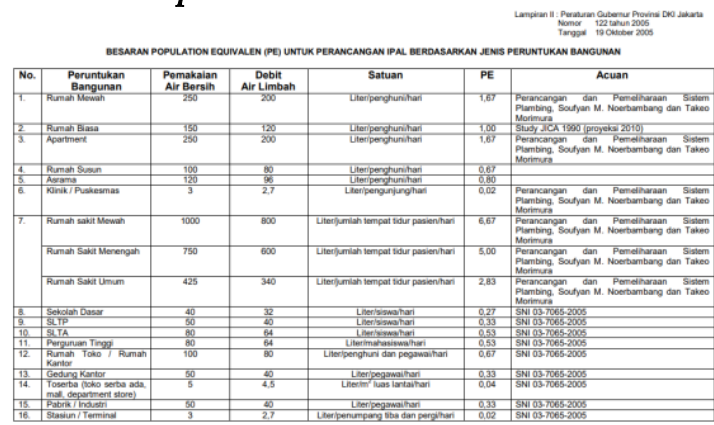




\section{ANALISIS \& PEMBAHASAN}

\section{Deskripsi Lokasi Perencanaan}

Perencanaan instalasi pengolahan air limbah domestik dilaksanakan di PT. Sumber Masanda Jaya di Kecamatan Bulakamba, Kabupaten Brebes Provinsi Jawa Tengah. Kecamatan Bulakumba adalah salah satu kecamatan yang ada di Kabupaten Brebes, dengan luas wilayah $1.902 \mathrm{~km}^{2}$. IPAL yang dibangun di PT. Sumber Masanda Jaya, Kelurahan Bulakumba Kabupaten Brebes Provinsi Jawa Tengah di peruntukan untuk limbah industri dan digunakan untuk pengolahan air limbah PT. Sumber Masanda Jaya. Kualitas effluen yang direncanakan untuk IPAL Domestik adalah $\mathrm{Ph} 6-9, \mathrm{BOD}_{5} 30 \mathrm{mg} / \mathrm{L}$ dan $\mathrm{COD} 80$ $\mathrm{mg} / \mathrm{L}$ sesuai baku mutu air limbah.

Di dalam proses pengolahan air limbah industri, khursusnya industri perminyakan dan petrokimia, sistem pengolahan limbah yang digunakan tergantung dari sumber air limbah, karakteristik air limbah, tingkat polusi, serta sistem saluran air limbah yang ada di dalam pabrik itu sendiri.

Secara umum pengolahan air limbah industri perminyakan terdiri dari tiga tahapan proses:

a) Pengolahan awal pemisahan minyak (preliminary oil removal)

b) Pemisahan minyak secara fisika-kimia (physicochemical oil removal)

c) Pengolahan sekunder dengan proses biologis (biological proses)

Perhitungaan jumlah karyawan $4000 \mathrm{~s} / \mathrm{d}$ 5000 orang.

Pemakaian air bersih untuk industry di peruntukan 40 liter/pegawai/orang.

Jumlah total limbah domestic yang dihasil kan $250 \mathrm{~m}^{3} /$ hari.

\section{Perencanaan Desain Struktur}

Diketahui denah pelat lantai bak Instalasi pengolahan air limbah IPAL di PT. Masanda Jaya Seperti Pada Gambar Berikut:

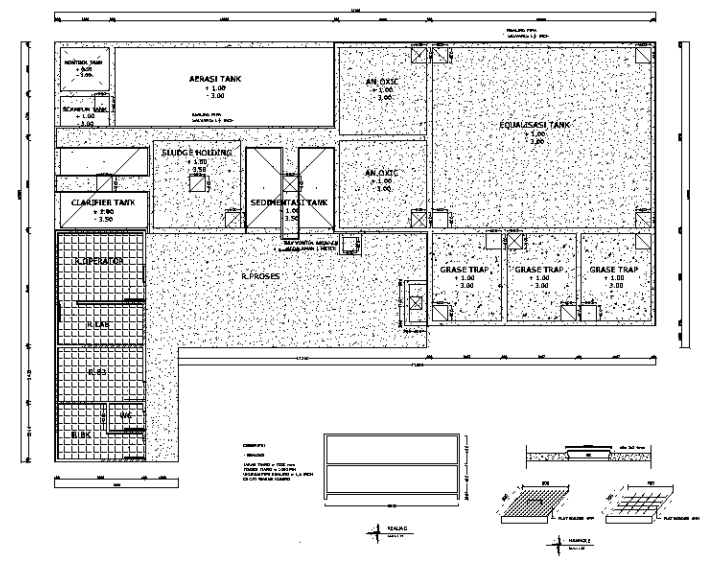

Data material:

Mutu Beton Fc $=30 \mathrm{Mpa}$

Mutu Baja Fy $=210 \mathrm{Mpa}$

Berat Isi Beton $=2400 \mathrm{~kg} / \mathrm{m}^{3}$

Berat Isi Air $\quad=1000 \mathrm{~kg} / \mathrm{m}^{3}$

\section{Perhitungan Pelat Lantai Dinding Bak}

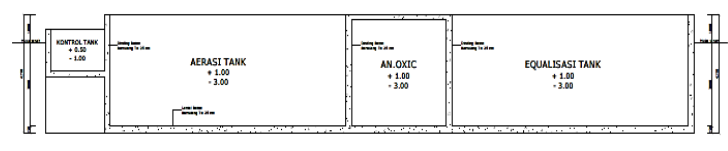

Data: Ly $=10.000$, Lx: 8250

Mutu baja yang digunakan $=210 \mathrm{Mpa}$

In $=$ Iy 10.000

$B \quad=\mathrm{Iy} / \mathrm{Ix}=10.000 / 8250=1,21$

Maka di dapat plat lantai minimum:

$\mathrm{H}(\min )>10.000(0,8+210 / 1500) / 36+9 \mathrm{x}$ $1,21=200,46 \mathrm{~mm}$

Maka di dapat plat lantai maximum:

$\mathrm{H}(\max )>10,000(0,8+210 / 1500) / 36$

$=261,11 \mathrm{~mm}$

Dari hasil perhitungan diatas diambil tebal Plat yaitu $250 \mathrm{~mm}=25 \mathrm{~cm}$.

Rencana diameter tulangan $=13 \mathrm{~mm}=$ $1,3 \mathrm{~cm}$.

$\mathrm{Fc}=30 \mathrm{Mpa}$

Fy $=210 \mathrm{Mpa}$

Selimut Beton $=40 \mathrm{~mm}=4 \mathrm{~cm}$

Tebal Plat $=250 \mathrm{~mm}=25 \mathrm{~cm}$

$\mathrm{Dx}=25-4-1 / 2.1=20,5 \mathrm{~cm}=0,21 \mathrm{~m}$

Dy $=25-4-1-1 / 2.1=19,5 \mathrm{~cm}=0,20 \mathrm{~m}$

$\mathrm{Q}$ tanah $=\square$ Tanah $\times 1 / 3 \mathrm{H}$

$=1700 \times 1 / 3 \times 3,5 \mathrm{~m}=1983 \mathrm{~kg} / \mathrm{m}$

Berat Kolom sendiri

$=2400 \mathrm{~kg} / \mathrm{m}^{3} \times 0,5 \mathrm{~m}=1200 \mathrm{~kg} / \mathrm{m}^{2}$

$=1200 \mathrm{~kg} / \mathrm{m}^{2} \times$ jumlah kolom

$=1200 \mathrm{~kg} / \mathrm{m}^{2} \times 12=14.400 \mathrm{~kg} / \mathrm{m}^{2}$ 
Pelat dinidng $=2400 \mathrm{~kg} / \mathrm{m}^{3} \times 0,25 \mathrm{~m}=600$ $\mathrm{kg} / \mathrm{m}^{2}$

Wult $=$ qtanah + berat sendiri kolom + plat dinding

$=1983 \mathrm{~kg} / \mathrm{m}^{2}+14.400 \mathrm{~kg} / \mathrm{m}^{2}+600 \mathrm{~kg} / \mathrm{m}^{2}=$ $16,983 \mathrm{~kg} / \mathrm{m}^{2}$

Berdasarkan buku grafik dan table perhitungan beton bertulang (SK.SNI table. 14).

$\mathrm{Ly} / \mathrm{Ix}=4 / 4=1$

Mlx $=0,040 \times$ Wult $x \mathrm{Ix}^{2}$

$=0,040 \times 16,983 \times(4)^{2}$

$=10.869,12 \mathrm{kgm}$

Mly $=0,040 \times$ Wult $\times$ Iy $^{2}$

$$
=0,040 \times 16,983 \times(4)^{2}
$$$$
=10.869,12 \mathrm{kgm}
$$

Mtx $=0,068 \times$ Wult $x \mathrm{Ix}^{2}$

$=0,068 \times 16,983 \times(4)^{2}$

$=18.477 \mathrm{kgm}$

$$
\begin{aligned}
\text { Mty } & =0,068 \times \text { Wult } \times \mathrm{Iy}^{2} \\
& =0,068 \times 16,983 \times(4)^{2} \\
& =18.477 \mathrm{kgm}
\end{aligned}
$$

Penulangan: di dapat $\mathrm{Mu}=18.477 \mathrm{kgm}$ Momen lapangan arah $\mathrm{x}$ dan $\mathrm{y}=\mathrm{Mu} / \mathrm{bd}_{\mathrm{x}}{ }^{2}$

$=18.477 / 1 .(0,155)^{2}$

$=443.909 \mathrm{Kg} / \mathrm{m}^{2}$

\section{Perhitungan Tulangan}

Tebal Pelat $\mathrm{h}=250 \mathrm{~mm}$

Penutup beton diambil, $S_{b}=40 \mathrm{~mm}$

Diperkirakan diameter tulangan D13mm.

\begin{tabular}{|c|c|}
\hline $\mathrm{Mu} / \mathbf{b}^{\mathbf{2}} \mathbf{}^{2}$ & $\mathrm{Fy}=400 \mathrm{Mpa}$ \\
\hline 400 & 0,0013 \\
\hline 500 & 0,0016 \\
\hline
\end{tabular}

Diinterpolasi:

$$
\begin{gathered}
\rho \mathrm{an}=\left(\frac{0.0016-0.0013}{(500-400)}\right) \times(440-400)+ \\
0.0013=0,00142 \\
\rho \min \quad=\left(\frac{1,4}{(f y)}\right)=\left(\frac{1,4}{(400)}\right)=0,0035 \\
\rho \max =0,75 \times 0,0035=0,0244
\end{gathered}
$$

Maka Digunakan $\rho \min =0,0035$

$p>p$ min , sehingga

Asl $=$ p.bd. $10^{6}$

$=0,00142 \cdot 1 \cdot 0,155 \cdot 10^{6}$

$=220,1 \mathrm{~mm}^{2}$

$=2,2 \mathrm{~cm}^{2}$

Digunakan tulangan D $13-150$
Dari perhitungan diatas maka digunakan baja tulangan berdiameter D 13 .

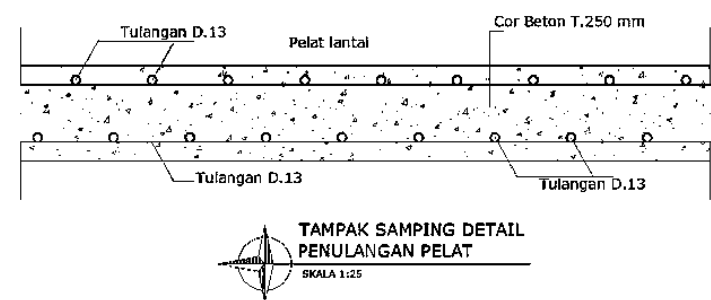

Debit Air Limbah: $250 \mathrm{~m}^{3} / \mathrm{hari}=10,41$ $\mathrm{m} 3 /$ jam

Volume Efektif Bak: 10,41 $\mathrm{m}^{3} / \mathrm{jam} \mathrm{x}$ waktu tinggal jam $=$ volume setiap bak $\mathrm{m}^{3}$

\section{Tahap Epoxy resin}

Setelah dinding bak instalasi pengolahan air limbah selesai dinding bak keseluruhan bagian dalam dilapisi dengan pelapis berupa epoxy atau resin, gunanya untuk menjaga struktur banguanan agar tahan, dikarenakan air limbah yang dihasilkan dapat merusak konstruksi sebab ini harus digunakan pelapis.

\section{Tahap Pengecatan}

Tahapan pengecatan bak dilakukan untuk mempercantik bak eksterior agar tidak hanya fungsi yang dihasilkan juga keindahan suatu bangunan dapat terlihat baik.

\section{Pekerjaan Alat-alat Instalasi Pengolahan Air Limbah (IPAL)}

Pekerjaan alat meliputi pemasangan pipa internal dan eksternal pada bak instalasi fungsinya untuk mengalirkan air limbah dengan baik secara fungsinya alat yang digunakan berupa pompa submersible, root blower, deffuser, mixer, ph indikator dan beberapa valve untuk mengatur debit aliran air yang ingin di proses. Setelah semua alat terpasang tinggal pemasangan instalasi listrik agar fungsi berjalan dengan semestinya, agar hasil limbah yang diproses dapat dihasilkan dengan maksimal.

\section{KESIMPULAN DAN SARAN \\ 1. Kesimpulan}

Setelah melakulan pelaksanaan perencanaan Instalasi Pengolahan Air Limbah IPAL di PT.Sumber Masanda Jaya Kabupaten Brebes Profinsi Jawa Tengah dapat di simpulkan bahwa bangunan tersebut mampu mengolah air limbah dengan baik sebagai berikut:

Didapat hitungan hasil uji lab dari nilai COD dan BOD5 untuk mendesain bak ter- 
sebut.

Didapat kapasitas bak yang di perlukan untuk sistem pengolahan air limbahnya agar mampu menampung volume air limbah dari inlet.

Efesinesi bak IPAL menggunakan 15 bak sistem pengolahan.

Secara umum proses pengolahan air limbah cair yang di laksanakan di Instalasi Pengolahan Air Limbah PT. Sumber Masanda Jaya sudah berjalan dengan baik dan optimal mutu lingkungan yang ditetapkan, dan efisiensi yang terjadi cukup baik. Berikut ini hasil efiseinsi proses yang terjadi pada IPAL berdasarkan hasil analisa laboratorium.

\section{Saran}

Adapun saran untuk pembangunan Instalasi Pengolahan Air Llimbah IPAL

PT.Sumber Masanda Jaya sebaiknya menggunakan Belf Press agar lumpur yang di hasilkan oleh sistem pengolahan air limbah tersebut dapat di fungsikan kembali dan memiliki harga jual yang tinggi sebab saat ini limpur tersebut belum ada perencanaan untuk menambah alat belt press untuk sistem pembakaran lumpur yang bisa di fungsikan kembali sebagai penghasilan dari sistem ipal tersebut.

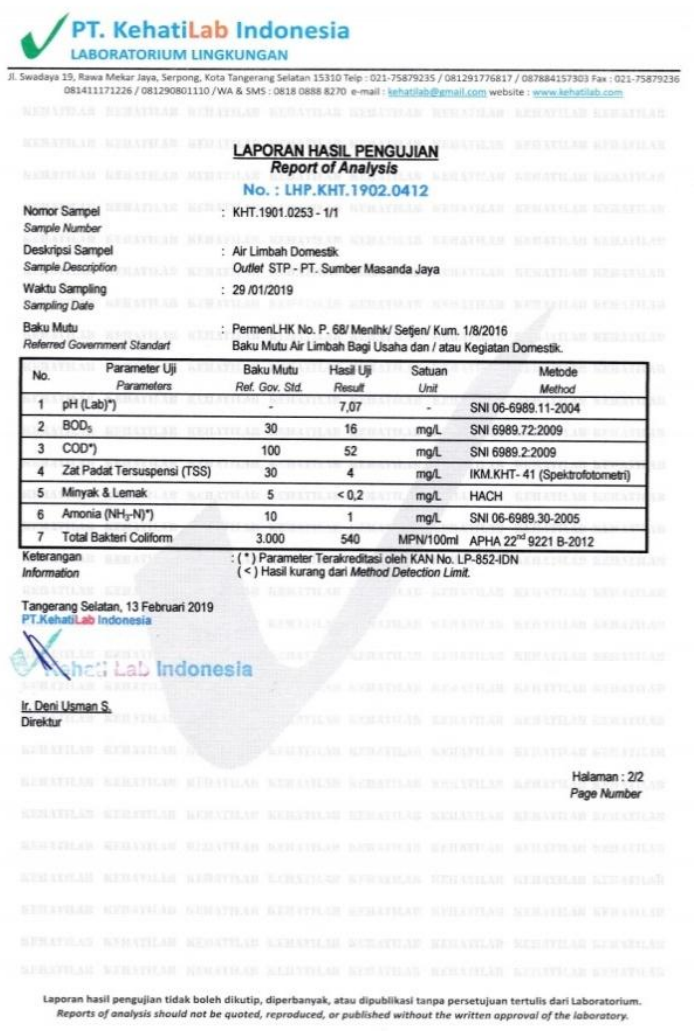

\section{DAFTAR PUSTAKA}

Buku Perencanaan Instalasi Pengolahan Air Limbah Domestik oleh Ir.Nusa Idaman Said, M.Eng. dan Ir.Wahyu Widayati, M.Si.

Peraturan Mentri Lingkungan Hidup dan Kehutanan

No.68/Menlhk/setjen/kum.1/8/2016

Tentang Buku Mutu Air Limbah.

Buku Teknologi Pengolahan Air Limbah, Nusa Idaman Said, M.Eng., Penerbit Erlangga. Jakarta.

Jurnal Evaliuasi Sistem Pengolahan Air Limbah (IPAL) Domestik, Diaz Palangda

Jurnal Saintek UNSA, Volume 1, Nomor 1 Februari 2106 oleh Isra Junna, Zulkarnaen, Alfian Rusdi. Analisis Konstruksi Instalasi Pengolahan Air Limbah IPAL.

Horan, N.J (1990). Biological Wastewater Treatment System. 